\title{
Emerging Zoonoses in Marine Mammals and Seabirds of the Northeast U.S.
}

\author{
A. Bogomolni ${ }^{1}$, J. Ellis ${ }^{2}$, R. Gast ${ }^{1}$, B. Harris ${ }^{2}$, M. Pokras ${ }^{2}$ and K. Touhey ${ }^{3}$ and M. Moore ${ }^{1}$ \\ Woods Hole Oceanographic Institution ${ }^{1}$ MS\# 50 Woods Hole, MA USA \\ Tufts University Cummings School of Veterinary Medicine, Grafton, MA. USA ${ }^{2}$ \\ Cape Cod Stranding Network P.O. Box 287 Buzzards Bay, MA ${ }^{3}$
}

\begin{abstract}
In the Northeast United States, marine vertebrates come into contact with each other and with humans through a variety of mechanisms which allow for the transfer of pathogens from one taxa to another. Though there are many ways in which humans come into contact with infectious agents, there is an inadequate understanding of the prevalence of clinical and subclinical zoonotic agents in the marine vertebrates of the Northeast United States. We are strengthening our understanding of the issue by targeting marine mammals and seabirds of New England and screening normal and diseased individuals of this ecosystem to establish a baseline prevalence of zoonotic agents in this ecosystem. Samples from stranded, bycaught and wild marine mammals and seabirds have been found to be positive for our screened pathogens. Most notable are the diseases found in bycaught marine mammals as well as wild caught individuals. Our current focus is specifically on influenza $A$ and $B$, brucellosis, leptospirosis, Giardia and Cryptosporidium. Samples for virology, bacterial screening and molecular screening are being archived and analyzed as practical. Our goal is to create an optimized PCRbased molecular detection protocol for the above agents.
\end{abstract}

\section{INTRODUCTION}

"Effective species protection should go beyond targeting individual species, and consider species relations within whole ecosystems as well as overall ecosystem functioning. Ecosystem health is identified as a necessary prerequisite for successful species protection in situ' (Baumgartner 2004).

This holds true for protecting the human species in our current era of relative insecurity concerning biological threats as it does in other animals. The threat of emerging zoonoses bears serious consideration on ecosystem health. Recent agents of real concern include AIDS from primates, influenza from birds, bovine spongiform encephalopathy from cows and Pfeisteria from dinoflagellates [1].

There is growing worldwide concern about pollution of coastal marine habitats and wild populations arising from the transfer of fecal material from humans and domesticated animals. Pathogens originating in human and animal feces are transported in runoff from agricultural, suburban and urban land surfaces, wastewater discharges and other sources to rivers and streams, which carry contaminated sediments to estuaries and coastal waters. For instance, tidal regions in the Georges River near Sydney, Australia, which are important recreational and shellfish production sites, had elevated concentrations of Giardia and Cryptosporidium from rainfall and sewage overflows after wet weather events [2]. Protozoa and other pathogens contaminate bathing beaches and infect shellfish, some of which are commercially harvested [3]. Marine vertebrates may become infected either via water-borne transmission or through consumption of infected prey such as shellfish or fish. Some animals, such as gulls, may become infected from foraging directly from sewage outfalls [4]. Thus, marine vertebrates are likely an important source of pathogens in marine waters. Yet, little is known about the role that marine wildlife play in the epidemiology of these pathogens.

In the Northeast United States, marine vertebrates come into contact with each other and with humans through a variety of mechanisms. These interactions may be direct or indirect. In particular, we are focusing on the direct vertebrate predators and scavengers that are associated with humans. These human activities include consumption of seafood, beach based recreation and handling of beached marine mammals, both by immediate response and in rehabilitation centers. Fish and shellfish are directly consumed by humans, while marine mammals and seabirds prey or scavenge on fish. Marine mammals and birds often haul out, strand or land on the same beaches that humans recreate upon. Coastal birds such as gulls often mix with humans in recreational settings and inland at human solid and liquid waste facilities and water supplies. Terrestrial and coastal mammals also mix as is the case with coyotes preying on seals around Cape Cod. Humans also encounter these taxa as fish processors and consumers and as bird and mammal rehabilitators. In many areas of the world, the association is more direct through hunting and consumption of marine mammals.

The interactions between these taxa and humans, are also indirect as seen in Figure 1. Humans coexist with coyotes, eat fish and occupy the same beaches upon which seals haul out and cetaceae strand. Coyotes eat seals, both dead and alive.
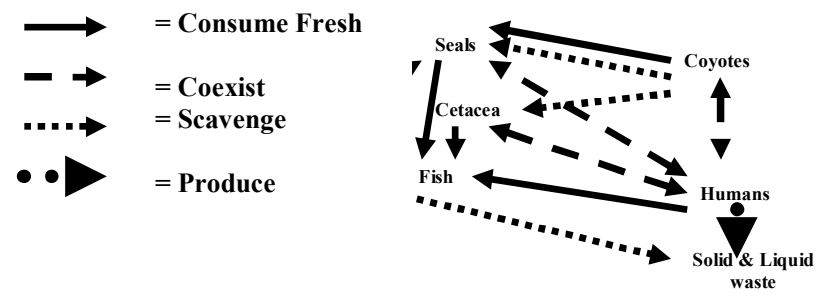

Figure 1. Schematic of key vertebrate inter-dependencies and potential zoonotic routes in the land/coastal waters ecosystem. Not shown is the public water supply impacted by gulls moving inland. 
Piscivorous birds such as some ducks and cormorants prey on fish such as young of winter flounder, while gulls scavenge solid waste from fast food restaurants and carcasses from beaches, and aggregate at wastewater treatment plants. In addition to disease, numerous threats contribute to mortality, including fisheries operations, organic pollutants, heavy metals, offshore development (potentially wind farms), and oil pollution. Many of these risks to seabirds also threaten the coastal and marine environments used by humans for respite and ecological services, as well as directly impacting human health. Seals eat fish amongst other prey, while winter flounder in turn congregate around terrestrial waste effluent outfalls. Thus the circle between producer, consumer, scavenger, and human waste discharger is of very limited size, allowing our examination of zoonotic potentials in many of the components.

The overall goal of this research project is to assess the prevalence of sub-clinical, and clinical if present, evidence of zoonoses in marine mammals and birds in the New England area of the Northeast United States. We have chosen to focus in particular on the prevalence of influenza, Leptospira, Brucella, Giardia and Cryptosporidium due to their importance as zoonotic organisms in humans, birds and marine mammals. We anticipate that this research will allow for a a better understanding of the potential for zoonoses to emerge from the ways that humans interface with vertebrates in the coastal marine ecosystem. Between October 2005 and June 2006, a total of 74 cases including a mix of stranded, bycaught and live marine mammals and birds have been sampled.

\section{MATERIALS AND METHODS}

\section{A. Tissue Samples}

Stranded and bycaught marine mammals were sampled for a suite of tissues at the Marine Research Facility, at the Woods Hole Oceanographic Institution (WHOI). These animals were provided by the NOAA observer program and the Cape Cod Stranding Network (CCSN). Serum from wild herring gulls and scat samples from wild seals were collected at Isle of Shoals, NH. Stranded birds were assessed and sampled at Tufts Veterinary School and SEANET.

\section{B. Sampling Material and Analysis}

To verify the capabilities of the WHOI in house molecular screen, each zoonotic agent is currently being screened at a designated recognized laboratory.

1) Viral swabs from lung and blow/nasal cavity collected in Hardy Diagnostics viral media and frozen at $-80^{\circ} \mathrm{F}$. Influenza samples sent to NVSL Madison, WI. for presence of H5N1 by PCR.

2) Bacterial culture screening and antibiotic resistance screening from thoracic and abdominal cavities collected in Amies gel for aerobic and anaerobic bacteria. Additional locations swabbed as needed. A selection of samples were initially collected using anaerobic specific media. Samples sent to IDEXX in Grafton, MA.

3) Frozen tissue and dry swabs for molecular screening were taken from from lung, liver, kidney, blow/nasal, spleen, brain, reproductive tissue, blood, feces, urine and gut. Tissue collected in $2 \mathrm{ml}$ centrifuge tubes and analyzed by PCR in house at WHOI

4) Cryptosporidium and Giardia scat/fecal/guano samples were collected in centrifuge tubes and tested first through Meriflour Flouresence Assay and by PCR in house at WHOI.

5) Brucella spp. samples of reproductive tissue, brain, and lung were collected in whirlpack bags and $50 \mathrm{ml}$ centrifuge tubes frozen at $-80{ }^{\circ} \mathrm{F}$. Samples then shipped to USDA in Ames, IA for culturing.

6) Leptospirosis samples of liver, kidney and spleen were collected in $50 \mathrm{ml}$ centrifuge tubes and stored frozen at $80{ }^{\circ} \mathrm{F}$. Samples then shipped to the Oklahoma Animal Diagnostic Laboratories (OADL) for PCR analysis.

\section{RESULTS}

A total of 74 cases, a mix of stranded, bycaught and live marine mammals and birds, were sampled since October 2005 (Figure 2). Preliminary results for each zoonotic agent were determined. Of the target pathogens, Cryptosporidium spp., Brucella spp. and Giardia spp. were isolated.

Bacterial cultures revealed a broad diversity of organisms known to be either zoonoses or noscomial agents. Noscomial agents being those that affect immunosupressed individuals or are introduced with invasive medical procedures. A surprising level of resistance to multiple antibiotics was also encountered. Table 5 shows a subset of the available sensitivity data that we are still processing. We are also working up a series of eider ducks that died in the winter of 2005-2006 on the shores of Martha's Vineyard, emaciated and heavily parasitized. We are working on the hypothesis that the eiders switched from a shellfish to a crab diet following an invasive crab species event, resulting in exposure to a heavy load of intermediates stage parasites. For each target zoonoses:

1 1) Viral sample analysis has been conducted on 17 samples for H5N1. No samples have resulting positive PCR results.

2) Bacterial culture screening resulted in a wide variety of aerobic and anaerobic bacteria with several human pathogens isolated (Table 1). Antibiotic resistant bacteria were common in several species of marine mammals. For example, a stranded common dolphin exhibited antibiotic resistant Klebsiella Pneumoniae, resistant to Ampicillin, Carbenicillin, Ticarcillin. One Pseudomonas included resistance to Augmentin, Ampicillin, Carbenicillin, Ceftiofur, Cephalothin, Ticarcillin and Tribrissen in a Cuvier's beaked whale.

3) The molecular screen on 69 samples verified results found by fluorescence assay and by the designated laboratories selected to test screen each agent. The Cryptosporidium 
molecular screen used only primers for $C$. parvum, and was not able to recognize the species of Cryptosporidium identified by the fluorescence assay. We have used our molecular screen to positively recognize Brucella, Giardia and Cryptosporidium. These results by taxa, screening methods and sample type can be found in Figure 3.

4) Positive identification of Cryptosporidium and Giardia by PCR and fluorescence assay was determined in 17 samples.

5) Cultures grown from frozen tissue for Brucella spp. at the OADL were negative, while PCR results for Brucella in house found 10 positive samples. Included in these positive samples were 2 positive gull samples.

6) PCR conducted on 17 samples Leptospirosis spp. by OADL were negative. These samples have not been confirmed by in house PCR tests.

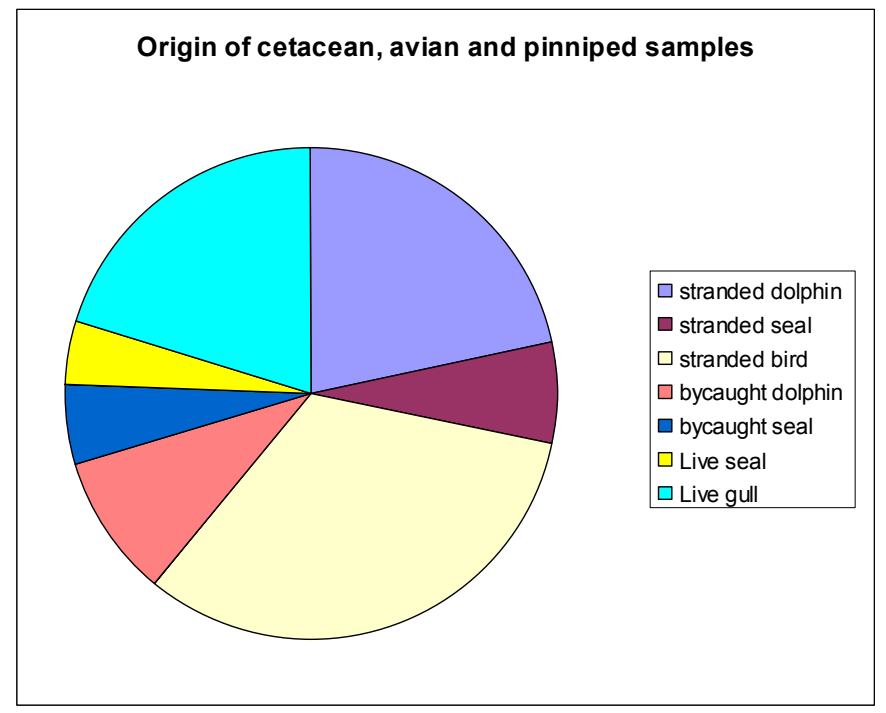

Figure 2. Proportion of samples from fbycaught, stranded and live animals.

\section{DISCUSSION}

The results obtained from this initial survey of zoonosis in the marine environment suggests there is a wide variety of diseases prevalent, though not necessarily pathogenic. Many of the zoonotic agents identified are found in both marine mammals and seabirds.

One suprising result of this survey is the prevalence of infectious zoonoses in bycaught animals, which are more often than not believed to represent a "healthy" subset of the population. This implies that the origin and method from which animals are obtained do not necessarily represent health, but rather, different environments perhaps for exposure.
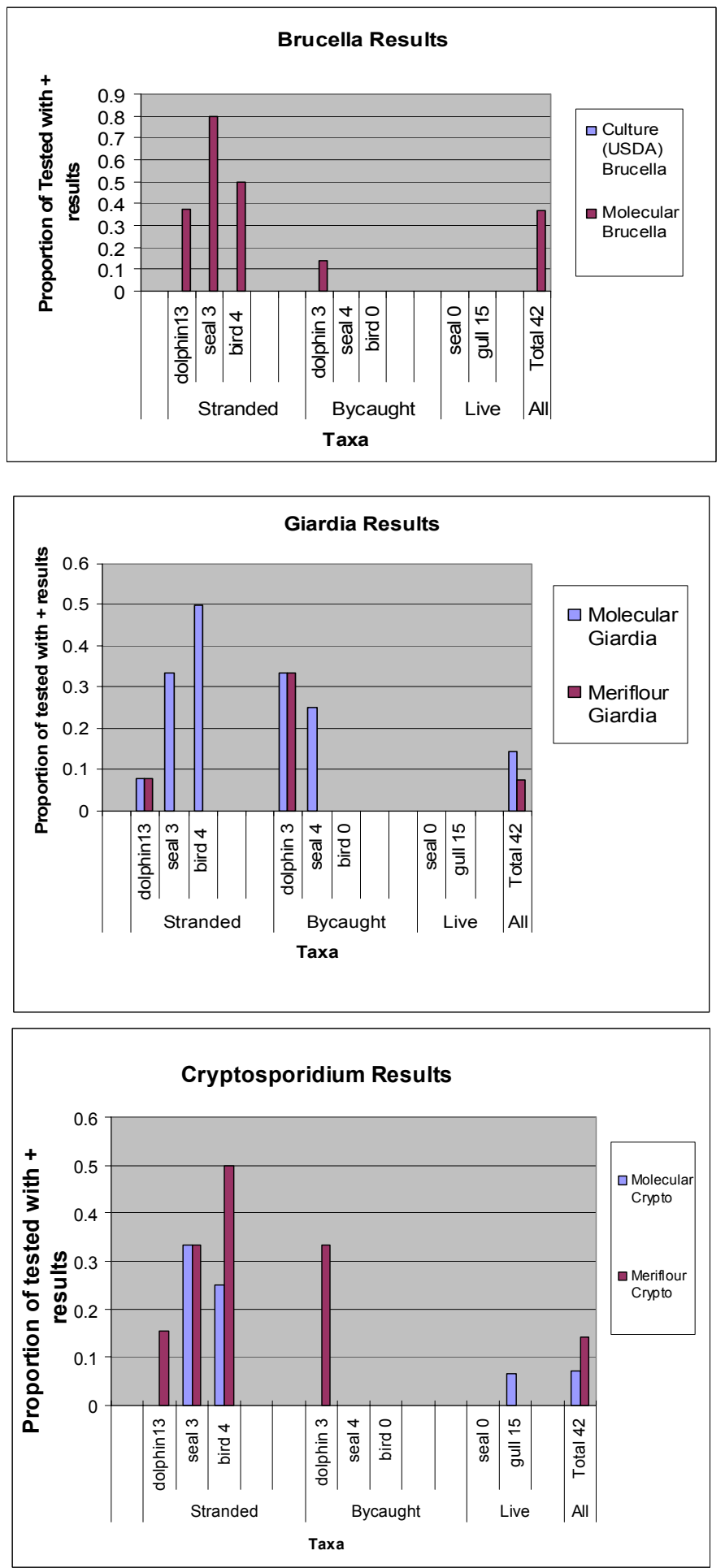

Figure 3. Brucella, Giardia and Cryptosporidium results determined by molecular screen (PCR) and flouresence microscopy. Numbers listed by taxa represent the number of animals tested. Percent of samples tested with positive results on $\mathrm{Y}$ axis. 
The observations made in this survey all raise important questions about the role, distribution and ecology of the relationships between pathogens and their hosts. Perhaps most remarkable are the diversity of organisms recovered from the one beaked whale in the series, and the diversity and prevalence of organisms recovered from herring gull oral and cloacal swabs.

Table 1.

Several zoonotic and noscomial organisms isolated by bacterial culture

\begin{tabular}{|ll|}
\hline Bacterium & Source(s) \\
Enterobacter cloacae & Stranded eider duck cloacal swab \\
Pantoea agglomerans & Herring gull cloacal and oral swab \\
Acinobacter baumannii & Stranded eider duck coelemic swab \\
& Herring gull oral swab \\
Pseudomonas oryzihabitans & Stranded beaked whale lung \\
Stenotrophomonas maltophilia & Bycaught harbor porpoise abdominal swab \\
Sphingobacterium multivorum & Bycaught harbor porpoise uterus \\
Serratia marcescens & Stranded harbor seal pup \\
Entercoccus faecalis & Red throated loon \\
Citrobacter braakii & Herring gull cloacal swab \\
Proteus penneri & Herring gull oral swab \\
Marine Pathogens & \\
\hline Photobacterium Damselae & Stranded beaked whale anal, thorax, urine, lymph \\
\hline
\end{tabular}

Of the target zoonoses, Cyptosporidium, Giardia and Brucella were detected. A wide diversity of other zoonotic and noscomial agents were also encountered. Of these isolates, the majority were found in a minority of species (herring gull, harbor seal and white sided dolphin).

The resistance data are still under analysis but of particular interest are isolates showing resistance to entrofloxacin and ciprofloxacin, the former was until recently used in poultry and often confers resistance to the latter, an important therapeutic agent. We plan on analyzing the source locations for each resistant isolate to see if there are any obvious patterns. Similarly chloramphenicol is a banned drug in the US, but still used in aquaculture elsewhere.

The widespread resistance in our isolates bear further examination and analysis in the context of what is known about this subject. It is also interesting that $5 / 10$ of the isolates that showed resistance were from bycaught animals, thus there appears to be a significant subclinical reservoir of multiply resistant organisms in offshore marine mammals. There is linkage between the prevalence of specific zoonotic agents in the different target host species, their antibiotic resistance patterns, and significant industrial sources of such pathogens and resistance such as solid municipal waste, sewage, intensive farming and aquaculture.

Origin of the pathogens found in this survey are still unknown. Several surveys conducted on isolates that have shown resistance have included chloramphenicol resistance and methicillin resistant Staphlococcus aureus (MRSA) have been identified using pulsed field gel electrophoresis (PFGE). This method has shown that transmission of two strains of MRSA is occurring in veterinary practices in Ireland and that one strain may have arisen from human hospitals. The source of the second strain remains to be determined [5].

In wild populations of animals, resistant bacteria are becoming more common. One pathogen of note includes Aeromonas hydrophila, which induced septicemia in a gray seal. The bacteria, which is pathogenic in immunosupressed seals, is not uncommon in seals, but usually is not pathogenic [6]. Immunosuppression and resistance were also found in samples from 93 harp seals caught in the Greenland sea in 1999. Serum was examined, and anti-Salmonella antibodies were found in the samples from two individuals (seroprevalence $2.2 \%)[7]$.

Similarly, cetaceans express antibiotic resistance. A serological survey of Tursiops in Charleston SC for reactivity to a number of bacteria including zoonoses was very variable but often positive [8].

With an increasing ability to fingerprint the genetic diversity of zoonotic agents, new species are being identified in marine mammals and seabirds and more cautions are being taken when working in an environment of high exposure. One such organism in our study is evidence for Brucella in marine birds. Marine mammal brucellosis has been identified as two new proposed Brucella species i.e. B. cetaceae and $S$. pinnipediae, and represents a new zoonotic threat, but the pathogenicity for humans of the different Brucella species found in cetaceans and pinnipeds still has to be clearly established [9]. Similarly, the Brucella species found in seabirds in this study need to be identified and the risk of zoonotic potential established.

There are many zoonoses of concern identified in past surveys including Bartonella henselae Toxoplasma gondii, Neospora caninum, Sarcocystis neurona, and Sarcocystis canis [10]. A seroligcal survey and review of the literature reveals many more infectious agents with unknown pathogenicity [11]. This study survey will continue through 2008, narrowing the focus on the most predominant zoonotic agents and those with highest antibiotic resistance.

We will likely focus our sampling on herring gulls at the Rochester NH landfill, and the Isle of Shoals, live harbor seals hauled out at the Isle of Shoals, and stranded and bycaught harbor seals and white sided dolphins as available. We will also begin serological analysis of selected agents in the context of the agents isolated from these species.

\section{ACKNOWLEDGMENT}

This research is supported by NOAA Ocean and Human Health Initiative Grant Number NA05NOS4781247 and NOAA Prescott Grant NA05NMF4391165.

\section{REFERENCES}


[1] Mahy B, Brown C (2000) Emerging zoonoses: crossing the species barrier. Review of Science and Technology 19: 33-40

[2] Ferguson CM, Coote BG, Ashbolt NJ, Stevenson IM (1996) Relationships between indicators, pathogens and water quality in an estuarine system. Water Research 30: 2045-2054

[3] Fayer R, Trout JM, Lewis EJ, Santin M, Zhou L, Lal A, Xiao L (2003) Contamination of Atlantic coast commercial shellfish with Cryptosporidium. Parasitology Research 89:141-145.

[4] Ferns PN, Mudge GP (2000) Abundance, diet and Salmonella contamination of gulls feeding at sewage outfalls. Water Research 34: 2653-2660 141-145

[5] O'mahoney, R. Y. Abbott, F.C. Leonard, B.K. Markey, Quinn, P.J. Pollock, S. Fanning, A.S.. (2005). Methicillin-resistant Staphylococcus aureus (MRSA) isolated fromanimals and veterinary personnel in Ireland. Veterinary Microbiology 109:285-296

[6] Krovacek, K., K. Huang, S. Sternberg, S. B. Svenson. (1998). Aeromonas hydrophila septicaemia in a grey seal (Halichoerus grypus) from the Baltic Sea: A case study. Comparative Immunology, Microbiology and Infectious Diseases 21:43-49

[7] Aschfalk, A., L. Folkhow, H. Rud, D. Denzin. (2002). Apparent
Seroprevalence of Salmonella spp. in Harp Seals in the Greenland Sea as Determined by Enzyme-linked Immunosorbent Assay. Veterinary Research Communications 26:523-530

[8] Beck, B. M., C. D. Rice. (2003). Serum antibody levels against select bacterial pathogens in Atlantic bottlenose dolphins, Tursiops truncatus, from Beaufort NC USA and Charleston Harbor, Charleston, SC, USA. Marine Environmental Research 55:161-179

[9] Godfroid, J., A. Cloeckaer, J. P. Liatuard, S. Kohler, D. Fretin, K. Walravens, B. Garin-Bastuji, J. J. Letesson. (2005). From the discovery of the Malta fever's agent to the discovery of a marine mammal reservoir, brucellosis has continuously been a re-emerging zoonosis. Veterinary Research 36:313-326

[10] Maggi, RG, Harms CA, Hohn AA, Pabst DA, Mclellan WA, Walton, WJ, D. Rotstein, E.Shwerdert. (2005). Bartonella henselae in porpoise blood. Emerg Infect Dis [serial on the Internet]

[11]] Dubey, J. P., N. J. T. R. Zarnke, S. K. Wong, W. VAN Bonn, M. Briggs, J. W. Davis, R. Ewing, M. Meense, O. C. H. Kwoket, AL., T. Volume116, ISSUE 4, 30 OCTOBER 2003, PAGES., ABSTRACT, A. K. T. G. N. C. S. N. S. C. A. A. T. S. O. W. S. S. L. MANATEE. (2003). Toxoplasma gondii, Neospora caninum, Sarcocystis neurona, and Sarcocystis canis-like infections in marine mammals. Veterinary Parasitology 116:275-295. 